\title{
ANALISIS SPASIAL INDUSTRI KECIL DAN MENENGAH DI PROPINSI NUSA TENGGARA TIMUR
}

\author{
Oleh: \\ Zainal Arifin \\ Fakultas Ekonomi \& Bisnis Universitas Muhammadiyah Malang \\ E-mail/No. Hp: azainala@yahoo.com/-
}

\begin{abstract}
This study aims to identify patterns of spatial concentration of Small and Medium Enterprises in East Nusa Tenggarajudging by the amount of labor and production as well as the factors that affect the employment period 20052009. Analysis tools used include: Spatial Analysis, Geographic Information Systems, and multiple linear regression. This study found that the distribution of Small and Medium Enterprises in East Nusa Tenggara is not evenly distributed geographically, when viewed from the employment and production quantities. In some counties and cities experienced employment and production quantities are high, while some others were experiencing employment and production quantities are low. It also reinforced the results of multiple linear regression analysis with panel data with the result that all explanatory variables X1 (business units), $X 2$ (investment), X3 (production) and X4 (raw materials) are able to explain to the employment of Small and Medium Industries in East Nusa Tenggara.
\end{abstract}

Keywords: Spatial analysis, small and medium industry

\begin{abstract}
Abstrak
Penelitian ini bertujuan untuk mengidentifikasi pola konsentrasi spasial Industri Kecil dan Menengah di propinsi Nusa Tenggara Timur dilihat dari jumlah tenaga kerja dan produksi serta faktor-faktor yang mempengaruhi penyerapan tenaga kerja periode 2005-2009. Alat analisis yang digunakan meliputi; Analisis Spasial, Sistem Informasi Geografis,dan regresi linear berganda. Penelitian ini menemukan bahwa distribusi Industri Kecil dan Menengah di Nusa Tenggara Timur memang tidak merata secara geografis, bila dilihat dari penyerapan tenaga kerja dan jumlah produksi. Di beberapa kabupaten dan kota mengalami penyerapan tenaga kerja dan jumlah produksi yang tinggi, sementara sebagian yang lain justru mengalami penyerapan tenaga kerja dan jumlah produksi yang rendah. Hal ini juga diperkuat dari hasil analisis regresi linear berganda dengan data panel dengan hasil bahwa semua variabel penjelas X1 (unit usaha), X2 (investasi), X3 (produksi) dan X4 (bahan baku) mampu menjelaskan terhadap penyerapan tenaga kerja Industri Kecil dan Menengah di Nusa Tenggara Timur.
\end{abstract}

Kata Kunci: Analisis spasial, industri kecil dan menengah 


\section{PENDAHULUAN}

Industri Kecil dan Menengah (IKM) merupakan salah satu sektor yang penting dalam perekonomian Indonesia. IKM menjadi sektor yang penting di Indonesia karena mampu menyediakan lapangan kerja, sehingga IKM menjadi sumber pendapatan primer maupun sekunder bagi banyak rumah tangga di Indonesia. Selain itu, IKM juga memiliki peran yang penting dalam perekonomian daerah dan mendorong pertumbuhan ekspor sektor non migas dan menjadi industri pendukung yang memproduksi komponen dan suku cadang bagi perusahaan besar.

Di era desentralisasi, pemerintah daerah berusaha untuk mengembangakan IKM di daerahnya sebagai salah satu usaha untuk mendorong pertumbuhan ekonomi daerah. Kita menyadari bahwa pengembangan IKM di daerah sangat erat kaitannya dengan dengan otonomi daerah. Otonomi daerah yang diimplementasikan semenjak tahun 2001 menyebabkan daerah memiliki kesempatan untuk mengatur daerahnya masing-masing. Pemerintah daerah mengelola penggunaan sumberdaya berdasarkan potensi lokal yang dimilikinya, termasuk mengatur IKM daerah. Basis kegiatan IKM di daerah adalah rakyat kecil. Karena itu IKM merupakan salah satu pondasi penting dalam perekonomian nasional, sehingga pemerintah daerah perlu memberikan perhatian yang lebih banyak pada pengembangan IKM.

Di lain sisi, IKM memiliki potensi berkembang dan telah terbukti mampu bertahan pada saat perekonomian menghadapi krisis, misalnya krisis 1997/98. Karena itu, pemerintah daerah harus menciptakan lingkungan bisnis yang kondusif sehingga memudahkan IKM dapat berkembang secara optimal. Kebijakan-kebijakan di setiap daerah harus dapat membantu IKM untuk berkembang.

Berdasarkan data tahun 1996 IKM di Indonesia mampu menyerap 221.972 tenaga kerja. Sedangkan tahun 2006 meningkat menjadi 496.628. Bila dilihat dari perbandingan peringkat penyerapan tenagakerja, Propinsi Nusa Tenggara Timur merupakan propinsi yang mengalami peningkatan penyerapan yang cukup bagus. Dari peringkat 25 pada tahun 1996 dengan jumlah 
tenaga kerja 540 orang, meningkat menjadi peringkat 15 pada tahun 2006 dengan jumlah 9.305 orang.

Bila dilihat dari tabel 1, perbandingan peringkat penyerapan tenagakerja, Propinsi Nusa Tenggara Timur merupakan propinsi yang mengalami peningkatan penyerapan yang cukup bagus. Dari peringkat 25 pada tahun 1996 dengan jumlah tenaga kerja 540 orang, meningkat menjadi peringkat 15 pada tahun 2006 dengan jumlah 9.305 orang. Kondisi ini menunjukkan bahwa keberadaan IKM di propinsi Nusa Tenggara Timur mampu memberikan kotribusi yang cukup besar terhadap penyerapan tenaga kerja. Penelitian ini akan mengetengahkan kajian tentang konsentrasi IKM di Propinsi Nusa Tenggara Timur dilihat dari jumlah penyerapan tenaga kerja dan produksi serta faktor-faktor yang mempengaruhi penyerapan tenaga kerja periode 2005-2009.

Suatu daerah umumnya dan suatu kota khususnya berkembang karena aglomerasi. Perkembangan kota-kota dan daerah-daerah tidak dapat terjadi tanpa aglomerasi (Isard,1975). Karena aglomerasi, perusahaan-perusahaan dapat melakukan produksi dengan biaya (rata-rata) yang lebih rendah atau yang sering disebut dengan penghematan aglomerasi (aglomeration economies).

Tabel 1. Perbandingan IKM Berdasarkan Jumlah Tenaga Kerja Per Provinsi Tahun 1996 dan 2006

\begin{tabular}{clrrlrrr}
\hline \multirow{2}{*}{ No } & \multicolumn{2}{c}{ Tahun 1996 } & \multicolumn{2}{c}{ Jml TK } & \multicolumn{2}{c}{ Tahun 2006 } & \multicolumn{2}{c}{ Jml TK } \\
& & (orang) & $\%$ & & 101.220 & 20,4 \\
\hline 1 & Jawa Tengah & 64.444 & 29,0 & Jawa Tengah & 89.251 & 18,0 \\
2 & Jawa Barat & 40.946 & 18,4 & Jawa Timur & 71.801 & 14,5 \\
3 & Jawa Timur & 38.745 & 17,5 & Jawa Barat & 18.980 & 3,8 \\
4 & D K I Jakarta & 19.469 & 8,8 & Sulawesi Selatan & 17.457 & 3,5 \\
5 & Sumatera Utara & 5.870 & 2,6 & Sumatera Utara & 16.024 & 3,2 \\
6 & Sulawesi Selatan & 4.945 & 2,2 & Nusa Tenggara Barat & 14.068 & 2,8 \\
7 & Sulawesi Utara & 4.716 & 2,1 & Lampung & 14.010 & 2,8 \\
8 & Bali & 4.650 & 2,1 & D K I Jakarta & 13.412 & 2,7 \\
9 & D I Yogyakarta & 4.251 & 1,9 & Nanggroe Aceh D & 12.909 & 2,6 \\
10 & Nusa Tenggara Barat & 3.920 & 1,8 & Banten & 12.253 & 2,5 \\
11 & Lampung & 3.685 & 1,7 & Bali & 11.639 & 2,3 \\
12 & Sumatera Selatan & 3.563 & 1,6 & Sumatera Barat & 10.794 & 2,2 \\
13 & Nanggroe Aceh D & 3.178 & 1,4 & Sumatera Selatan & &
\end{tabular}


Analisis Spasial Industri Kecil .... (Zainal Arifin)

\begin{tabular}{|c|c|c|c|c|c|c|}
\hline 14 & Riau & 2.891 & 1,3 & D I Yogyakarta & 10.293 & 2,1 \\
\hline 15 & Sumatera Barat & 2.626 & 1,2 & Nusa Tenggara Timur & 9.305 & 1,9 \\
\hline 16 & Maluku & 2.131 & 1,0 & Kalimantan Selatan & 9.042 & 1,8 \\
\hline 17 & Jambi & 2.081 & 0,9 & Sulawesi Tenggara & 6.717 & 1,4 \\
\hline 18 & Kalimantan Selatan & 2.005 & 0,9 & Kalimantan Barat & 6.657 & 1,3 \\
\hline 19 & Kalimantan Timur & 1.539 & 0,7 & Riau & 6.299 & 1,3 \\
\hline 20 & Sulawesi Tenggara & 1.164 & 0,5 & Sulawesi Utara & 5.130 & 1,0 \\
\hline 21 & Sulawesi Tengah & 1.024 & 0,5 & Sulawesi Tengah & 4.897 & 1,0 \\
\hline 22 & Kalimantan Barat & 981 & 0,4 & Kalimantan Timur & 4.839 & 1,0 \\
\hline 23 & Bengkulu & 977 & 0,4 & Jambi & 4.822 & 1,0 \\
\hline 24 & Kalimantan Tengah & 944 & 0,4 & Kalimantan Tengah & 4.248 & 0,9 \\
\hline 25 & Nusa Tenggara Timur & 540 & 0,2 & Bengkulu & 2.976 & 0,6 \\
\hline 26 & Maluku Utara & 402 & 0,2 & Gorontalo & 2.856 & 0,6 \\
\hline 27 & Timor Timur & 285 & 0,1 & Maluku & 2.782 & 0,6 \\
\hline 28 & & & & Papua & 2.775 & 0,6 \\
\hline 29 & & & & Sulawesi Barat & 2.373 & 0,5 \\
\hline 30 & & & & Kepulauan Riau & 2.100 & 0,4 \\
\hline 31 & & & & Bangka Belitung & 1.934 & 0,4 \\
\hline 32 & & & & Maluku Utara & 1.550 & 0,3 \\
\hline 33 & & & & Papua Barat & 1.215 & 0,2 \\
\hline Tota & & 221.972 & 100 & Total & 496.628 & 100 \\
\hline
\end{tabular}

Sumber: Dihitung dari BPS (1996; 2006)

Ada dua macam agglomeration economies; Pertama, penghematan lokalisasi (Localization economies) terjadi bila biaya total rata-rata (produksi) dari perusahaanperusahaan yang sejenis (dalam suatu industri) pada lokasi yang sama turun, bila jumlah produksi dari industri itu naik. Kedua, penghematan urbanisasi (urbanization economies) terjadi bila biaya total rata-rata (produksi) dari tiap perusahaan turun, bila jumlah produksi dari berbagai industri disuatu lokasi yang sama naik (Supono, 1999:15).
Penghematan lokalisasi terjadi karena tiga alasan; pemilihan input bersama dalam jumlah besar dari perusahaan-perusahaan sejenis dalam lokasi yang sama dari pemasok input yang sama, ekonomi pasar tenaga kerja (pekerja mudah berganti pekerjaan dilokasi yang sama), dan komunikasi ekonomi (mudahnya pertukaran informasi dan penyebaran teknologi antara pekerja-pekerja dari perusahaan-perusahaan).

Penghematan urbanisasi terjadi untuk alasan-alasan yang sama seperti penghematan lokalisasi (Supono, 1999:16). 
Pendekatan lain adalah mengkaitkan aglomerasi sebagai suatu bentuk spasial dengan konsep "penghematan aglomerasi" melalui konsep eksternalitas. Para ekonom biasanya membedakan antara: (1) penghematan internal dan eksternal (internal economies dan external economies); (2) penghematan akibat skala ekonomis dan cakupan (economies of scale dan economies of scope) (Scott \& Storper, 1992: 6-7).

Penghematan internal adalah suatu hubungan pengurangan biaya secara internal di dalam suatu perusahaan atau pabrik. Seberapa jauh pengurangan biaya dapat dicapai pada suatu perusahaan tergantung apakah efisiensi dapat ditingkatkan atau dipertahankan. Beberapa faktor yang berperanan dalam pengurangan biaya secara internal meliputi: pembagian kerja (spesialisasi), digantinya tenaga manusia dengan mesin, melakukan sub-kontrak beberapa aktifitas proses produksi kepada perusahaan lain, dan menjaga titik optimal operasi yang meminimalkan biaya (Toyne, 1974: 59-62). Sedang penghematan eksternal merupakan pengurangan biaya yang terjadi akibat aktifitas di luar lingkup perusahaan atau pabrik.
Penghematan akibat skala ekonomi muncul karena perusahaan menambah produksi dengan cara memperbesar pabrik (skala ekonomi). Penghematan biaya terjadi dengan meningkatkan skala pabrik sehingga biaya produksi per unit dapat ditekan. Ini berbeda dengan penghematan akibat cakupan yang terjadi karena sejumlah aktivitas atau sub-unit usaha secara internal maupun eksternal dapat dilakukan pada saat yang bersamaan sehingga menghemat biaya. Skala ekonomis pada tingkat perusahaan agaknya ditransformasikan dalam keuntungan yang meningkat (increasing returns) pada tingkat perkotaan melalui interaksi kumulatif dari keterkaitan ke depan dan belakang.

Markusen (1996) menyatakan bahwa aglomerasi merupakan suatu lokasi yang "tidak mudah berubah" akibat adanya penghematan eksternal yang terbuka bagi semua perusahaan yang letaknya berdekatan dengan perusahaan lain dan penyedia jasajasa; dan bukan akibat kalkulasi perusahaan atau para pekerja secara individual. Weber (1929) adalah salah seorang yang pertama-tama mengajukan pertanyaan mengapa 
pabrik-pabrik cenderung berlokasi saling berdekatan. Menurut Weber, ekonomi aglomerasi (deglomerasi) menentukan apakah industri terkonsentrasi di suatu tempat atau tersebar di lebih dari satu tempat (lihat Kuncoro, 2002).

Kuncoro (2002), melakukan studi tentang dinamika spasial industri manufaktur di Indonesia dengan tahun pengamatan 1976 sampai 1999. Studi ini menegaskan bahwa aglomerasi industri besar dan sedang sangat berhubungan dengan konsentrasi perkotaan di Jawa. Aglomerasi industri manufaktur dan populasi yang besar telah berkembang di Jabotabek dan Greater Bandung di bagian barat, dan Greater Surabaya di bagian timur pulau Jawa. Daerahdaerah tersebut menawarkan daya aglomerasi yang kuat, yang pada akhirnya akan menarik baik orang maupun perusahaan-perusahaan.

Juoro (1989), menganalisa faktor-faktor penentu bagi konsentrasi di Indonesia (sekaligus ia juga menganalisa konsentrasi industri di Filipina). Dengan mempergunakan fungsi serupa CES yang dikembangkan oleh Dhrymes (1965), ia melakukan regresi upah (wages) sebagai fungsi dari output dan tenaga kerja. Dari parameter-parameter estimasi diperoleh tingkat homogenitas (degree of homogeneity) yang merepresentasikan skala ekonomi atau ekonomi lokalisasi untuk tingkat industri. Hasilnya memperlihatkan bahwa hampir semua industri tiga dijit di Indonesia mempunyai tingkat homogenitas lebih besar daripada satu. Keadaan ini merupakan pertanda pentingnya ekonomi lokalisasi bagi terkonsentrasinya industri di daerah perkotaan besar (large urban areas).

Fonomena yang sekarang banyak berkembang pada bidang industri adalah terbentuknya kluster industri geografis dimana antar perusahaan yang ada didalamnya memiliki hubungan saling ketergantungan yang kuat. Konsentrasi perusahaan-perusahaan yang memiliki kesamaan proses produksi maupun saling melengkapi kebutuhan input, mendominasi pasar dunia belakangan ini. Sebuah perusahaan akan memilih lokasi kerja yang berdekatan dengan perusahaan penghasil bahan bakunya. Sebuah perusahaan akan memilih lokasi kerja yang berdekatan supplier, konsumen, 
maupun kompetitor mereka karena hal tersebut akan menurunkan biaya transaksi, serta membuat proses produksi menjadi lebih efesien dan membuat usaha adopsi teknologi terbaru menjadi lebih mudah.

Kluster digunakan untuk menggambarkan konsentrasi perusahaan-perusahaan yang mampu menghasilkan sinergi karena faktor kedekatan geografis maupun hubungan ketergantungan diantara mereka walaupun bukan merupakan kumpulan perusahaan yang mampu menyerap tenaga kerja secara dominan.

Studi yang paling sering dijadikan acuan oleh pendekaan ini adalah hasil studi Porter (1990) yang menetapkan empat diamond. Diamond-diamond itu adalah persaingan antar perusahaan dalam kluster, permintaan lokal, peranan industri terkait dan industri pendukung, serta kondisi faktor produksi. Walaupun teorinya berdasarkan pada sistim nasional tetapi dia menekankan bahwa faktor kedekatan lokasi adalah hal yang penting dan daerah dalam banyak hal lebih berperan daripada bangsa dalam menciptakan keuntungan kompetitif.
Porter mengemukakan dua tipe kluster yaitu kluster vertikal dan kluster horisontal. Kluster vertikal terbenuk oleh industri yang memiliki hubungan pembeli dan penjual. Sedangkan kluster horisontal terbentuk oleh industri yang memiliki kesamaan pasar produknya, teknologi, tenaga kerja, serta sumber daya alam (Porter, 1990).

Sedangkan menurut Rosenfeld (1997), kluster industri adalah industri yang terkonsentrasi secara geografis yang bergerak pada bidang yang sama, atau merupakan yang terkait, maupun industri pendukung yang memiliki hubungan komunikasi, pengunaan infrastruktur yang sama, tenaga kerja dan jasa serta menghadapi peluang dan ancaman yang sama.

Beberapa ciri kluster (Hunphrey \& Schmitz, 1995,p.3) yaitu: pertama, Kluster regional adalah konsentrasi beberapa perusahaan pada lokasi dan sektor tertentu. Konsentrasi geografis biasanya merupakan konsentrasi tenaga kerja dan sering digunakan sebagai representasi pasar tenaga kerja daerah dan kemudian dijadikan sebagai pembanding pasar tenaga kerja nasional. 
Kedua, Sebuah kluster biasanya terdiri dari beberapa perusahaan (biasanya perusahaan kecil dan menengah) yang bergerak pada industri yang dominan dalam perekonomian sebuah negara. Ketiga, Perusahaan-perusahaan dalam kluster membentuk jaringan produksi lokal yang menggabungkan subkontraktor pada level produksi yang sama dan kemudian external ekonomi akan muncul ketika beberapa perusahaan melakukan spesialisasi pada beberapa fase dalam jaringan produksi. Perusahaan-perusahaan itu berkerja bersama seperti layaknya sebuah unit produksi yang sangat besar. Keempat, Perusahaan-perusahaan itu mengadopsi sistem produksi yang fleksibel sehingga mereka memiliki peralatan produksi yang fleksibel. Menggunakan tenaga kerja yang fleksibel ataupun bergantung pada subkontraktor maupun perusahaan lain dalam mengadopsi perubahan volume produksi maupun model produk.

Kelima, Pada sebuah distrik industri, aktivitas sebuah kluster ditentukan oleh kondisi sosial dan kebudayaan daerah tersebut. Keenam, pada beberapa kluster akan tumbuh sistem inovasi regional. Perusahaanperusahaan akan bekerja sama dalam melakukan inovasi berdasarkan asas kepercayaan dan aktivitas inovasi ini akan dilakukan oleh sebuah lembaga formal seperti pusat jasa industri, pusat pengembangan teknologi maupun pusat pelatihan tenaga kerja. Dengan demikian maka kluster akan memiliki kemampuan untuk meningkatkan produksinya. Berdasarkan uraian ini, maka penelitian ini akan menganalisis industri kecil dan menengah di Nusa Tenggara Timur.

\section{METODE PENELITIAN}

Tahapan analisis yang pertama dilakukan dengan mengikuti langkah sebagai berikut: pertama, Memberikan peringkat dari terbesar sampai terkecil dari data yang akan dianalisis. Kedua, Mencari rata-rata data dan standar deviasi. Ketiga, Membagi 4 kategori dengan menjumlahkan rata-rata dengan standar deviasi dan mengurangkan rata-rata dengan standar deviasi, sehingga terbentuk 4 katerogi yaitu: 1) Kategori peringkat I di atas ratarata di tambah standar deviasi; 2) Kategori peringkat II di antara rata- 
rata dan penambahan rata-rata dengan standar deviasi; 3) Kategori peringkat III di antara rata-rata dan pengurangan rata-rata dengan standar deviasi; dan 4) Kategori peringkat IV di bawah pengurangan rata-rata dengan standar deviasi.

Analisis yang kedua yaitu menggunakan Sistem Informasi Geografi (SIG). SIG digunakan untuk memetakan data jumlah tenaga kerja, unit usaha, produksi dan investasi berdasarkan peringkat pada analisis spasial. SIG pada dasarnya adalah suatu tipe sistem informasi, yang memfokuskan pada penyajian dan analisis realitas geografis. Titik beratnya adalah mengelola dan menganalisis data dengan suatu sistem informasi.

SIG pada dasarnya adalah jenis khusus sistem informasi, yang memperhatikan representasi dan manipulasi realita geografi. SIG mentransformasikan data menjadi informasi dengan mengintegrasikan sejumlah data yang berbeda, menerapkan analisis fokus, dan menyajikan output dalam rangka mendukung pengambilan keputusan (Juppenlatz \& Tian, 1996: bab 1). Dalam studi ini, akan mengikuti beberapa prosedur standar dalam merancang dan menggunakan SIG, yaitu: pengumpulan data, pengolahan data awal, konstruksi basis data, analisis dan kajian spasial, dan penyajian grafis.

Tahapan analisis yang ketiga yaitu analisis regresi dengan data panel. Dengan mempertimbangkan keung-gulan-keunggulan data panel maka dalam penelitian ini akan digunakan pendekatan data panel dalam upaya mengestimasi model yang ada. Teknik yang dipakai adalah OLS (Ordinary Least Square). Adapun spesifikasi model panel yang akan diestimasi dalam penelitian ini adalah sebagai berikut:

$Y_{r t}=\beta_{0}+\beta_{1} X_{1 r t}+\beta_{2} X_{2 r t}+\beta_{3} X_{3 r t}+\beta_{4} X_{4 r t}+e_{r t}$

dimana Yrt adalah penyerapan tenaga kerja di kabupaten/kota selama tahun 2005-2009; X1, X2, X3, X4 masingmasing adalah unit usaha, investasi, produksi dan bahan baku.

\section{HASIL DAN PEMBAHASAN}

Dari perhitungan dengan analisis diskriptif memperlihatkan bahwa distribusi penyerapan tenaga kerja pada tingkat kabupaten/kota di Nusa Tenggara Timur memiliki 
kecondongan positif (positive pergeseran meliputi 1 kota dan 2 skewness) dan "tidak normal" secara kabupaten, yaitu Kota Kupang, statistik dengan nilai kurtosis dan Kabupaten Kupang dan Kabupaten skweness sebesar 3,75 dan 3,84. Manggarai. Sedangkan yang Demikian pula bila dilihat dari jumlah produksi, dengan nilai kurtosis dan skewness sebesar 15,50 dan 3,79 . Kondisi ini menunjukkan adanya ketidakmerataan dalam distribusi penyerapan tenaga kerja maupun jumlah produksi yang dihasilkan pada tingkat kabupaten di Provinsi Nusa Tenggara Timur. Di beberapa kabupaten dan kota mengalami penyerapan tenaga kerja dan jumlah produksi yang tinggi, sementara sebagian yang lain justru mengalami penyerapan tenaga kerja dan jumlah produksi yang rendah.

Pada tabel 2 terlihat bahwa tahun 2005 distribusi penyerapan tenaga kerja Industri Kecil dan Menengah di Nusa Tenggara Timur yang tergolong peringkat sangat tinggi meliputi 1 kota dan 2 kabupaten yaitu Kota Kupang, Kabupaten Sumba Timur dan Kabupaten Timor Tangah Selatan. Pada tahun 2009 distribusi penyerapan tenaga kerja di Nusa Tenggara Timur yang tergolong peringkat sangat tinggi mengalami tergolong peringkat tinggi meliputi 5 kabupaten, yaitu Kabupaten Rote Ndao, Timor Tengah Selatan, Ngada, Sumba Timur dan Kabupaten Sumba Barat.

Dari awal sampai akhir pengamatan terlihat bahwa penyerapan tenaga kerja di seluruh kabupaten dan kota mengalami peningkatan secara terus menerus. Namun secara prosentase, kontribusi kabupaten dan kota terhadap penyerapan tenagakerja Provinsi Nusa Tenggara Timur, beberapa kabupaten dan kota ada yang selalu mengalami peningkatan, sementara yang lain ada juga yang mengalami penurunan dan fluktuasi prosentase kontribuasinya. Kontribusi pada penyerapan tenaga kerja yang selalu mengalami penigkatan adalah pada Kabupaten Rote Ndao, Kabupaten. Ngada dan Kabupaten Sumba Barat. Sedangkan kabupaten dan kota lainnya mengalami penurunan maupun berfluktuasi kontribusinya. Pada tahun 2005, Kota Kupang, Kabupaten Sumba Timur, Kabupaten 
Timor Tengah Selatan dan Kabupeten

Timur Tengah Utara memberikan kontribusi masing-masing, 20,31\%, $14,71 \%, \quad 12,23 \%$ dan $7,87 \%$.

Kontribusi ke empat kabupaten dan kota ini mampu menyumbangkan lebih dari $50 \%$ terhadap Provinsi
Nusa Tenggara Timur. Kondisi ini menunjukkan bahwa kontribusi distribusi penyerapan tenaga kerja di Provinsi Nusa Tenggara Timur terkonsentrasi pada wilayah tersebut di atas.

Tabel 2. Penyerapan Tenaga Kerja Industri Kecil dan Menengah Pada Tingkat Kabupaten/Kota di Nusa Tenggara Timur, 2005-2009

\begin{tabular}{llrrrrr}
\hline \multirow{2}{*}{ No } & \multicolumn{1}{c}{ Kabupaten/Kota } & 2005 & 2006 & \multicolumn{1}{c}{ Tahun } & \multicolumn{1}{c}{2008} & \multicolumn{1}{c}{2009} \\
\hline 1 & Kota Kupang & 1.910 & 1.932 & 1.935 & 3.061 & 4.810 \\
2 & Kab. Kupang & 419 & 550 & 419 & 1.485 & 2.551 \\
3 & Kab. Rote Ndao & 147 & 231 & 231 & 1.069 & 1.265 \\
4 & Kab. Timor Tengah Selatan & 1.150 & 1.400 & 1.750 & 1.505 & 1.622 \\
5 & Kab. Timor Tengah Utara & 740 & 799 & 857 & 805 & 753 \\
6 & Kab. Belu & 437 & 546 & 428 & 1.420 & 276 \\
7 & Kab. Alor & 158 & 158 & 158 & 165 & 387 \\
8 & Kab. Lembata & 554 & 631 & 708 & 838 & 940 \\
9 & Kab. Flores Timur & 362 & 362 & 381 & 663 & 944 \\
10 & Kab. Sikka & 414 & 329 & 614 & 687 & 751 \\
11 & Kab. Ende & 521 & 572 & 589 & 641 & 731 \\
12 & Kab. Ngada & 222 & 382 & 586 & 1.055 & 1.524 \\
13 & Kab. Manggarai & 596 & 909 & 949 & 905 & 2.631 \\
14 & Kab. Manggarai Barat & 171 & 178 & 187 & 408 & 440 \\
15 & Kab. Sumba Timur & 1.383 & 1.377 & 1.037 & 1.440 & 1.533 \\
16 & Kab. Sumba Barat & 270 & 270 & 335 & 917 & 1.498 \\
\hline
\end{tabular}

Sumber: Data diolah

Pada tahun 2009, Kota Kupang, Timur. Kondisi ini menunjukkan Kabupaten Kupang dan Kabupaten bahwa kontribusi distribusi Manggarai memberikan kontribusi penyerapan tenaga kerja pada tahun masing-masing, 19,51\%, 10,67\%, dan 2009 di Provinsi Nusa Tenggara 10, 51\%. Kontribusi ke tiga Timur juga terkonsentrasi pada kabupaten dan kota ini mampu beberapa wilayah saja. menyumbangkan lebih dari $40 \%$ terhadap Provinsi Nusa Tenggara

Dari kontribusi penyerapan tenaga kerja industri kecil dan 
menengah pada tingkat kabupaten dan kota di Provinsi Nusa Tenggara Timur tahun 2005 hingga 2009 menunjukkan adanya pergeseran kontribusi maupun jumlah kontribusinya. Pada tahun 2005 Kota Kupang, Kabupaten Sumba Timur, Kabupaten Timor Tengah Selatan dan Kabupeten Timur Tengah Utara memberikan kontribusi terbesar, namun pada tahun 2009 mengalami pergeseran kontribusi. Hanya Kota Kupang yang masih mampu memberikan kontribusi terbesar. Penurunan kontribusi pada Kota Kupang dan pergeseran kontribusi pada kabupaten yang lainnya menunjukkan adanya peningkatan aktivitas pada industri kecil dan menengah pada beberapa kabupaten di Provinsi Nusa Tenggara Timur.

Tabel 3. Kontribusi Penyerapan Tenaga Kerja Industri Kecil dan Menengah Pada Tingkat Kabupaten/Kota di Nusa Tenggara Timur, 2005-2009 (dalam \%)

\begin{tabular}{clrrrrr}
\hline No & \multicolumn{1}{c}{ Kabupaten/Kota } & 2005 & 2006 & 2007 & 2008 & \multicolumn{1}{c}{ Tahun } \\
\hline 1 & Kota Kupang & 20,31 & 18,36 & 17,60 & 17,94 & 19,51 \\
2 & Kab. Kupang & 4,46 & 5,23 & 3,81 & 8,70 & 10,35 \\
3 & Kab. Rote Ndao & 1,56 & 2,19 & 2,10 & 6,27 & 5,13 \\
4 & Kab. Timor Tengah Selatan & 12,23 & 13,30 & 15,92 & 8,82 & 6,58 \\
5 & Kab. Timor Tengah Utara & 7,87 & 7,59 & 7,80 & 4,72 & 3,05 \\
6 & Kab. Belu & 4,65 & 5,19 & 3,89 & 8,32 & 1,12 \\
7 & Kab. Alor & 1,68 & 1,50 & 1,44 & 0,97 & 1,57 \\
8 & Kab. Lembata & 5,89 & 6,00 & 6,44 & 4,91 & 3,81 \\
9 & Kab. Flores Timur & 3,85 & 3,44 & 3,47 & 3,89 & 3,83 \\
10 & Kab. Sikka & 4,40 & 3,13 & 5,58 & 4,03 & 3,05 \\
11 & Kab. Ende & 5,54 & 5,43 & 5,36 & 3,76 & 2,96 \\
12 & Kab. Ngada & 2,36 & 3,63 & 5,33 & 6,18 & 6,18 \\
13 & Kab. Manggarai & 6,34 & 8,64 & 8,63 & 5,30 & 10,67 \\
14 & Kab. Manggarai Barat & 1,82 & 1,69 & 1,70 & 2,39 & 1,78 \\
15 & Kab. Sumba Timur & 14,71 & 13,08 & 9,43 & 8,44 & 6,22 \\
16 & Kab. Sumba Barat & 2,87 & 2,57 & 3,05 & 5,37 & 6,08 \\
\hline
\end{tabular}

Sumber: Data diolah

Pada tabel 4 terlihat bahwa peringkat sangat tinggi meliputi 1 tahun 2005 jumlah produksi Industri kota dan 2 kabupaten yaitu Kota Kecil dan Menengah di Nusa Kupang, Kabupaten Kupang dan Tenggara Timur yang tergolong Kabupaten Timor Tangah Selatan. 
Sedangkan yang tergolong peringkat tinggi meliputi 4 kabupaten, yaitu Kabupaten Rote Ndao, Flores Timur, Sikka dan Kabupaten Sumba Timur.

Pada tahun 2009 produksi Industri Kecil dan Menengah di Nusa Tenggara Timur yang tergolong peringkat sangat tinggi juga mengalami pergeseran peringkat meliputi 1 kota dan 3 kabupaten, yaitu Kota Kupang, Kabupaten Timur Tengah Utara, Flores Timur dan Kabupaten Sikka. Sedangkan yang tergolong peringkat tinggi meliputi 5 kabupaten, yaitu Kabupaten Kupang, Rote Ndao, Belu, Manggarai, dan Kabupaten Sumba Timur.

Dari awal sampai akhir pengamatan terlihat bahwa jumlah produksi di seluruh kabupaten dan kota mengalami peningkatan secara fluktuasi pada setiap tahunnya. Kontribusi kabupaten dan kota terhadap jumlah produksi Provinsi Nusa Tenggara Timur, beberapa kabupaten dan kota ada yang mengalami peningkatan kemudian tahun berikutnya mengalami penurunan. Pada tahun 2005 hingga tahun 2009, Kota Kupang mampu memberikan kontribusi lebih dari $50 \%$, selebihnya tersebar di 15 kabupaten. Kondisi ini menunjukkan bahwa kontribusi distribusi jumlah produksi di Provinsi Nusa Tenggara Timur terkonsentrasi di Kota Kupang.

Tabel 4. Jumlah Produksi Industri Kecil dan Menengah Pada Tingkat Kabupaten/Kota di Nusa Tenggara Timur, 2005-2009 (Ribuan Rp)

\begin{tabular}{rlrrrrr}
\hline \multirow{2}{*}{ No } & \multicolumn{1}{c}{ Kabupaten/Kota } & \multicolumn{3}{c}{ Tahun } \\
& & \multicolumn{1}{c}{2005} & \multicolumn{1}{c}{2006} & \multicolumn{1}{c}{2007} & \multicolumn{1}{c}{2008} & \multicolumn{1}{c}{2009} \\
\hline 1 & Kota Kupang & 230.098 & 145.145 & 153.495 & 208.548 & 218.357 \\
2 & Kab. Kupang & 5.119 & 13.466 & 14.067 & 16.626 & 16.568 \\
3 & Kab. Rote Ndao & 6.044 & 6.044 & 7.881 & 7.444 \\
4 & Kab. Timor Tengah Selatan & 2.119 & 5.008 & 5.835 & 3.257 & 3.865 \\
5 & Kab. Timor Tengah Utara & 22.773 & 22.773 & 20.811 & 23.449 & 25.074 \\
6 & Kab. Belu & 3.254 & 5.933 & 10.643 & 9.424 & 10.079 \\
7 & Kab. Alor & 1.517 & 1.517 & 1.517 & 3.052 & 4.607 \\
8 & Kab. Lembata & 4.796 & 9.274 & 8.563 & 3.948 & 2.572 \\
9 & Kab. Flores Timur & 8.132 & 9.161 & 17.996 & 27.506 & 27.406 \\
10 & Kab. Sikka & 7.002 & 7.020 & 25.800 & 23.299 & 25.081 \\
11 & Kab. Ende & 3.962 & 3.962 & 2.192 & 3.181 & 3.263 \\
12 & Kab. Ngada & 1.775 & 2.405 & 2.630 & 2.668 & 2.820 \\
13 & Kab. Manggarai & 4.608 & 3.163 & 6.732 & 5.716 & 6.785 \\
14 & Kab. Manggarai Barat & 437 & 330 & 1.507 & 2.473 & 4.141 \\
15 & Kab. Sumba Timur & 7.446 & 8.141 & 5.707 & 9.408 & 9.946 \\
16 & Kab. Sumba Barat & 2.246 & 2.453 & 4.238 & 4.533 & 5.082 \\
\hline
\end{tabular}


Analisis Spasial Industri Kecil .... (Zainal Arifin)

Sumber: Data diolah

$\begin{array}{llllll}\text { Jumlah } & 228.387 & 245.840 & 290.775 & 355.040 & 373.090\end{array}$

Tabel 5. Kontribusi Jumlah Produksi Industri Kecil dan Menengah Pada Tingkat Kabupaten/Kota di Nusa Tenggara Timur, 2005-2009 (\%)

\begin{tabular}{rlrrrrr}
\hline No & \multicolumn{1}{c}{ Kabupaten/Kota } & 2005 & 2006 & 2007 & 2008 & 2009 \\
\hline 1 & Kota Kupang & 56,96 & 59,04 & 52,79 & 58,74 & 58,53 \\
2 & Kab. Kupang & 10,12 & 5,48 & 4,84 & 4,68 & 4,44 \\
3 & Kab. Rote Ndao & 2,24 & 2,46 & 2,08 & 2,22 & 2,00 \\
4 & Kab. Timor Tengah Selatan & 0,93 & 2,04 & 2,01 & 0,92 & 1,04 \\
5 & Kab. Timor Tengah Utara & 9,97 & 9,26 & 7,16 & 6,60 & 6,72 \\
6 & Kab. Belu & 1,42 & 2,41 & 3,66 & 2,65 & 2,70 \\
7 & Kab. Alor & 0,66 & 0,62 & 0,52 & 0,86 & 1,23 \\
8 & Kab. Lembata & 2,10 & 3,77 & 2,94 & 1,11 & 0,69 \\
9 & Kab. Flores Timur & 3,56 & 3,73 & 6,19 & 7,75 & 7,35 \\
10 & Kab. Sikka & 3,07 & 2,86 & 8,87 & 6,56 & 6,72 \\
11 & Kab. Ende & 1,73 & 1,61 & 0,75 & 0,90 & 0,87 \\
12 & Kab. Ngada & 0,78 & 0,98 & 0,90 & 0,75 & 0,76 \\
13 & Kab. Manggarai & 2,02 & 1,29 & 2,32 & 1,61 & 1,82 \\
14 & Kab. Manggarai Barat & 0,19 & 0,13 & 0,52 & 0,70 & 1,11 \\
15 & Kab. Sumba Timur & 3,26 & 3,31 & 1,96 & 2,65 & 2,67 \\
16 & Kab. Sumba Barat & 0,98 & 1,00 & 1,46 & 1,28 & 1,36 \\
& & 100,00 & 100,00 & 100,00 & 100,00 & 100,00 \\
\hline
\end{tabular}

Sumber: Data diolah

\section{Tabel 6. Hasil Estimasi Faktor-faktor Penentu Penyerapan Tenaga Kerja Industri Kecil dan Menengah di Nusa Tenggara Timur, 2005-2009}

\begin{tabular}{lrr}
\hline Variabel Independen & Model & Uji t Hitung \\
\hline Konstanta ( C) & $-0,997$ & $-3,354^{*}$ \\
X1 (Unit Usaha) & 0,627 & $12,700^{*}$ \\
X2 (Investasi) & 0,099 & $2,170^{* *}$ \\
X3 (Produksi) & 0,139 & $2,051^{* *}$ \\
X4 (Bahan baku) & 0,126 & $2,071^{* *}$ \\
Adjusted R & \multicolumn{2}{c}{0,833} \\
F-statistik & \multicolumn{2}{c}{99,646} \\
DW-statistik & \multicolumn{2}{c}{1,44} \\
Jumlah obserasi & \multicolumn{2}{c}{80} \\
\hline
\end{tabular}

Catatan:

* menunjukkan signifikansi statistik pada derajat kepercayaan $1 \%$

** menunjukkan signifikansi statistik pada derajat kepercayaan $10 \%$

Dari pengamatan 2005 hingga penyerapan tenaga kerja berbeda 2009, terlihat bahwa kontribusi dengan kontribusi jumlah produksi 
pada tingkat kabupaten dan kota di Provinsi Nusa Tenggara Timur. Di Kota Kupang, kontribusi penyerapan tenaga kerja produksi pada industri kecil dan menengah berkisar 20\% namun kontribusi produksi bisa mencapai lebih dari 50\%. Kondisi ini menunjukkan bahwa aktifitas produksi pada produksi industri kecil dan menengah di Kota Kupang, lebih banyak mengadalkan teknologi daripada penggunaan tenagakerja seperti yang dilakukan di beberapa kabupaten di Provinsi Nusa Tenggara Timur. Sementara pada kabupaten selain Kota Kupang masih lebih banyak menggunakan tenagakerja dalam proses produksi industri kecil dan menengah.

Pembahasan berikutnya yaitu mengenai faktor-faktor penentu penyerapan tenaga kerja industri kecil menengah di Nusa Tenggara Timur.

Hasil estimasi memberikan dukungan empiris untuk model penyerapan tenaga kerja pada tabel 6 berdasarkan variabel penjelas $\mathrm{X} 1$ (unit usaha), X2 (investasi), X3 (produksi) dan X4 (bahan baku).

Variabel dependen adalah penyerapan tenaga kerja industri kecil menengah untuk masing-masing kabupaten/kota di Propinsi Nusa Tenggara Timur periode 2005-2009. Angka statistik $\mathrm{t}$ disajikan dalam tanda kurung. Berikut ini akan diuraikan interpretasi hasil analisis ekonometrika berdasarkan model di atas.

X1 (Unit Usaha) yang positif mengindikasikan bahwa bila ada penambahan jumlah unit usaha (perusahaan) maka akan menyebabkan meningkatnya tingkat penyerapan tenaga kerja di industri kecil menengah.

X2 (Investasi) menunjukkan hubungan yang positif dan signifikan mengindikasikan bahwa semakin tinggi investasi telah mendorong penyerapan tenaga kerja industri kecil menengah yang lebih besar.

X3 (Produksi) mempunyai hubungan positif dan signifikan mengindikasikan bahwa semakin tinggi produksi akan semakin mendorong penyerapan tenaga kerja di sektor industri kecil menengah.

X4 (Bahan baku) mempunyai hubungan positif dan signifikan mengindikasikan bahwa semakin tinggi produksi akan semakin mendorong penyerapan tenaga kerja di sektor industri kecil menengah. 
Terkonsentrasinya penyerapan

\section{PENUTUP}

Secara umum dari hasil penelitian ini dapat diambil kesimpulan, bahwa pertumbuhan Industri Kecil dan Menengah di Nusa Tenggara Timur pada periode pengamatan 2005-2009 tidak merata antar kabupaten. dan jumlah produksi.

Dari analisis spasial terlihat bahwa distribusi Industri Kecil dan Menengah di Nusa Tenggara Timur memang tidak merata secara geografis, bila dilihat dari penyerapan tenaga kerja dan jumlah produksi. Di beberapa kabupaten dan kota mengalami penyerapan tenaga kerja dan jumlah produksi yang tinggi, sementara sebagian yang lain justru mengalami penyerapan tenaga kerja dan jumlah produksi yang rendah.

Hal ini juga diperkuat dari hasil analisis regresi linear berganda dengan data panel dengan hasil bahwa semua variabel penjelas X1 (unit usaha), X2 (investasi), X3 (produksi) dan X4 (bahan baku) mampu menjelaskan terhadap penyerapan tenaga kerja Industri Kecil dan Menengah di Nusa Tenggara Timur. tenaga kerja dan jumlah produksi Industri Kecil dan Menengah pada beberapa kabupaten dan kota tertentu, sementara sebagaian yang lain justru memiliki tingkat kepadatan yang rendah, pada akhirnya akan semakin meningkatkan kesenjangan antardaerah. Kondisi ini akan terus berjalan, manakala perintah daerah maupun pusat sebagai penentu kebijakan tidak segera mengantisipasi permasalahan tersebut.

Pentingnya pembuatan klusterkluster bagi lokasi Industri Kecil dan Menengah menuntut para penentu kebijaksanaan haruslah menaruh perhatian yang lebih besar pada pembangunan prasarana (infrastruktur) yang mempunyai peranan cukup besar dalam mencipatkan kluster-kluster Industri Kecil dan Menengah. Selain itu untuk sektor Industri Kecil dan Menengah juga perlu diberikan aksesibilitas yang memadai baik ke pasar maupun ke faktor produksi. Perbaikan prasarana dan aksesibilitas memungkinkan Industri Kecil dan Menengah untuk berlokasi di daerah perkotaan yang lebih kecil atau bahkan di daerah pedesaan. 
Tersedianya prasarana transportasi, seperti jalan bebas hambatan, dan sistem kemunikasi yang baik, relatif mudahnya diperoleh jasa-jasa teknik dan keuangan, tersedianya tenaga kerja yang memadai dan relatif rendahnya harga tanah menupakan faktor-faktor yang antara lain menarik industri untuk berlokasi di daerah lain.

\section{DAFTAR PUSTAKA}

Aziz, I. J. (1994). Ilmu Ekonomi Regional dan Beberapa Aplikasinya di Indonesia (Regional Economics and Its Some Applications in Indonesia). Jakarta:

Brulhart, M. (1998a). Economic Geography, Industry Location and Trade: The Evidence. The World Economy, 21(6), 775801.

Badan Pusat Statistik (BPS) Propinsi Nusa Tenggara Timur, Data Industri Kecil dan Menengah tahun 2005-2009.

Chinitz, B. (1961). Contrasts in Agglomeration: New York and Pittsburg. American Economic Review, 51(2), 279-89.

Crampton, G., \& Evans, A. (1992). The Economy of an Agglomeration: The Case of London. Urban Studies, 29(2), 259-71.
Dharmapatni, I. A. I., \& Firman, T. (1995). Problems and Challenges of Mega-Urban Regions in Indonesia: The Case of Jabotabek and the Bandung Metropolitan Area. In T. G. McGee \& I. M. Robison (Eds.), The MegaUrban Regions of Southeast Asia . Vancouver: UBC Press.

Dinas Perindustrian dan Perdagangan (Disperindag) Propinsi Nusa Tenggara Timur, Data Industri Kecil dan Menengah tahun 2005-2009.

Isard, W. (1960). Methods of Regional Analysis: An Introduction to Regional Science. Cambridge and London: M.I.T Press.

Krugman, P. (1996). Urban Concentration: The Role of Increasing Returns and Transport Costs. International Regional Science Review, 19(1\&2), 5-30.

Kuncoro, M. (2000). Ekonomi Pembangunan: Teori, Masalah dan Kebijakan. (1st ed.). Yogyakarta: UPP AMP YKPN.

Kuncoro, M. (2001). Metode Kuantitatif: Teori dan Aplikasi untuk Bisnis dan Ekonomi. Yogyakarta: UPPAMP YKPN.

Kuncoro, M., Adji, A., \& Pradiptyo, R. (1997). Ekonomi Industri: Teori, Kebijakan, dan Studi Empiris di Indonesia (Industrial Economics: Theory, Policy, and Empirical 
Studies in Indonesia).

Yogyakarta: Widya Sarana Informatika.

Pangestu, M. (1992). Indonesia: Toward Non-oil Exports. In H. Hughes (Ed.), The Dangers of Export Pessimism (pp. 25076). San Fransisco: ICS Press.

Pangestu, M. (1997, December 1718). Domestic Competition Policy. Paper presented at the Sustaining Economic Growth in Indonesia: A Framework for the Twenty-First Century, Porter, M. E. (1998a). Clusters and the New Economics of Competition. Harvard Business Review, NovemberDecember(6), 77-91.

Zeitlin, J. (1992). Industrial Districts and Local Economic Generation: Overview and Comment. In F. Pyke \& W. Sengenberger (Eds.), Industrial Districts and Local Economic Regeneration. Geneva: ILO. 